Article

\title{
Study on Sintering Characteristics of Ultra-Poor Vanadium-Titanium Magnetite
}

\author{
Songtao Yang ${ }^{1,2}$, Mi Zhou ${ }^{2, *}$, Tao Jiang ${ }^{2}$ and Xiangxin Xue ${ }^{2}$ \\ 1 School of Materials and Metallurgy, University of Science and Technology Liaoning, Anshan 114051, China; \\ yangsongtao1984@163.com \\ 2 School of Metallurgy, Northeastern University, Shenyang 110819, China; jt1970@ustl.edu.cn (T.J.); \\ xxxing39@163.com (X.X.) \\ * Correspondence: zhoumineu@163.com; Tel.: +86-13889856506
}

Citation: Yang, S.; Zhou, M.; Jiang,

T.; Xue, X. Study on Sintering Characteristics of Ultra-Poor Vanadium-Titanium Magnetite. Minerals 2021, 11,515. https:// doi.org/10.3390/min11050515

Academic Editor: Saija Luukkanen

Received: 28 March 2021

Accepted: 6 May 2021

Published: 13 May 2021

Publisher's Note: MDPI stays neutral with regard to jurisdictional claims in published maps and institutional affiliations.

Copyright: (c) 2021 by the authors. Licensee MDPI, Basel, Switzerland. This article is an open access article distributed under the terms and conditions of the Creative Commons Attribution (CC BY) license (https:// creativecommons.org/licenses/by/ $4.0 /)$.

\begin{abstract}
Artificial rich ore for blast furnace use can be produced by sintering ultra-poor vanadiumtitanium magnetite (PVTM) with a high-grade iron concentrate. Here, acid $(R=0.33,0.50)$, selffluxing $(R=1.10)$, and high-basicity $(R=2.60)$ PVTM sinters were produced in a sinter pot. Their performances were determined using the comprehensive index. The microstructures of the PVTM sinter were observed by metallographic microscope and scanning electron microscopy equipped with an energy dispersion spectrum (SEM-EDS). The results suggest that the acid PVTM sinter had a low flame front speed, low productivity, an uneven size distribution, and poor softening properties. It did have a high tumble index (TI) and low-temperature reduction disintegration index (RDI). The self-fluxing PVTM sinter had the worst performance (TI, RDI, reducibility index (RI)), while the high-basicity PVTM sinter had the highest flame front speed, highest productivity, a reasonable size distribution, excellent softening properties, and satisfactory TI and RDI values. The main consolidation form of the acid sinter was crystal stock, the main bonding phase of the self-fluxing sinter was silicate, and the main bonding phase of the high-basicity sinter was silico-ferrite of calcium and aluminum (SFCA). The comprehensive index values (from high to low) were the high-basicity $(R=2.60)$, acid $(R=0.50)$, natural acid $(R=0.33)$, and self-fluxing $(R=1.10)$ PVTM sinters. When the production capacity of the acid pellet was in shortage, the acid PVTM sinter $(R=0.50)$ could be produced by the surplus from the sinter plant. This replaced a part of the acid pellet and the burden structural model of the blast furnace smelting vanadium so the titanium burden could adopt a 'high-basicity PVTM sinter + acid V-Ti pellet + acid $(\mathrm{R}=0.50)$ PVTM sinter'.
\end{abstract}

Keywords: acid sinter; self-fluxing; basicity; sinter; vanadium-titanium magnetite; blast furnace

\section{Introduction}

Vanadium-titanium magnetite (V-Ti magnetite), one kind of paragenetic ore composed of iron, vanadium, and titanium, etc., is an important mineral resource with a high commercial value. The ore is extensively distributed globally with large reserves, mainly in the Panzhihua and Chengde regions of China, exceeding 5 billion tons [1-5]. After years of mining, the vanadium-titanium magnetite with high iron content in the shallow part of the main mineral fields in the Chengde area has been basically mined out. However, with the continuous progress of mining and beneficiation technology, a large amount of vanadium-titanium magnetite with a low iron content in the mineral field is worth highlighting. It is estimated that the resources of ultra-poor vanadium-titanium magnetite (PVTM) in the Chengde area exceed 10 billion tons [6-9]. Through sintering, the PVTM can be used together with a high-grade iron concentrate to produce a man-made rich ore for a blast furnace $(\mathrm{BF})$.

The V-Ti magnetite has been classified as a typical polymetallic paragenic ore that is difficult to treat and utilize due to its many drawbacks [10-12]. The disadvantages 
associated with V-Ti magnetite include a poor grade, a fine mineral crystal size, a complicated phase structure, and numerous mineral components. The main burden of the V-Ti sinter lies within the $\mathrm{BF}$, where it exhibits poor intensity and reduction degradation when compared to the ordinary sinter at the same basicity $\left(\mathrm{R}=\omega(\mathrm{CaO}) / \omega\left(\mathrm{SiO}_{2}\right)\right)$. Previous research promoted the properties of the V-Ti sinter by optimizing the V-Ti blends, the granulation process, the sintering behaviors, and the flux including $\mathrm{MgO}, \mathrm{CaO}$, and $\mathrm{B}_{2} \mathrm{O}_{3}$. The optimized high basicity V-Ti sinter $(\mathrm{R}=2.50-2.60)$ has good properties and a high productivity. To ensure the quality of the V-Ti sinter, the basicity of the sinter is increased to $2.5-2.6[13,14]$, which needs more acid pellets to maintain the constant blast furnace slag basicity. Regarding the shortage of the production capacity of the acid pellet, in many research institutions and iron and steel companies the acid sinter was produced using a surplus sinter plant and by replacing the acid pellet to be added into a blast furnace [15-17]. This achieved good results and economic benefits.

The current study proposes that some acid PVTM sinters or self-fluxing PVTM sinters produced by a surplus sinter plant could replace some of the acid V-Ti pellets that are added in the blast furnace. Prior to this, the proper acid PVTM sinter, the self-fluxing PVTM sinter, and the high-basicity PVTM sinter should be prepared, and their different properties and productivities should be analyzed. This would allow for the evaluation of the single acid PVTM sinter, the self-fluxing PVTM sinter, and the high-basicity PVTM sinter to be conducted to determine their application in BF smelting. Through these steps, a novel burden structural model for smelting V-Ti could be proposed.

Here, an acid sinter $(R=0.33,0.50)$, self-fluxing sinter $(R=1.10)$ and high-basicity PVTM sinter $(R=2.60)$ were produced in a sinter pot. Additionally, the flame front speed, weight loss, yield ( $>5 \mathrm{~mm}$ ), tumble strength (TI), low-temperature reduction degradation index (RDI), reduction index (RI) and softening properties were determined and analyzed. Moreover, the comprehensive index method was used to calculate the comprehensive index to evaluate the acid sinter, self-fluxing, and high-basicity PVTM sinter. Moreover, the microstructures of the sinters were investigated by metallographic microscope and scanning electron microscopy equipped with an energy dispersion spectrum (SEM-EDS).

\section{Materials and Methods}

\subsection{Raw Materials}

The PVTM magnetite used in this study was a mixed-ore that was evenly mixed between 4 kinds of PVTM magnetite (A, B, C, D) obtained from different mine resources in Chengde, Hebei province, China. The other raw materials were supplied by Jianlong Iron and Steel Group Company, China. The Yangdi ore (YD), Malaysia ore (ML), and Zichanfen ore (ZF) are common iron concentrates without vanadium and titanium elements. The return fines, waste slag, and BF slag are all waste materials discharged by the plant. The quicklime is added to the sintering raw materials to adjust the basicity. The chemical composition of the raw materials and the coke breeze are listed in Tables 1 and 2. The TFe in Table 1 represents total iron, that is the proportion of various forms of iron in the ore. Listed in Table 1, the total iron (TFe) contents of 4 kinds of PVTM magnetite are higher than that of ores $\mathrm{ML}$ and $\mathrm{YD}$, and the $\mathrm{TiO}_{2}$ content of PVTM magnetite varies from $1.45 \%$ to $3.15 \%$ along with the $\mathrm{V}_{2} \mathrm{O}_{5}$ content, which varies from $0.37 \%$ to $0.59 \%$. Therefore, it will have a significant effect on the iron grade of the sinter. 
Table 1. Chemical composition of raw materials (mass fraction, \%).

\begin{tabular}{cccccccc}
\hline Raw Materials & $\mathbf{T F e}$ & $\mathbf{C a O}$ & $\mathbf{S i O}_{\mathbf{2}}$ & $\mathbf{V}_{\mathbf{2}} \mathbf{O}_{\mathbf{5}}$ & $\mathbf{A l}_{\mathbf{2}} \mathbf{O}_{\mathbf{3}}$ & $\mathbf{T i O}_{\mathbf{2}}$ & $\mathbf{M g O}$ \\
\hline Mixed PVTM ore & 43.08 & 3.46 & 8.82 & 2.49 & 3.44 & 2.98 & 3.52 \\
YD ore & 66.06 & 1.2 & 2.57 & & 5.63 & 0.21 & 0.15 \\
ML ore & 51.71 & 0.21 & 6.57 & & 8.48 & 0.33 & 0.15 \\
ZR ore & 65.55 & 0.46 & 3.04 & & 0.65 & 0.09 & 3.5 \\
BF dust & 51.71 & 0.21 & 6.57 & & 8.48 & 0.33 & 0.15 \\
Waste slag & 30.68 & 2.44 & 16.97 & 1.22 & 1.53 & 9.81 & 2.82 \\
Quicklime & & 79 & 2.52 & & & & 3.5 \\
\hline
\end{tabular}

Table 2. Proximate analysis of the coke breeze and the chemical compositions of ash (mass fraction, \%).

\begin{tabular}{|c|c|c|c|c|c|c|c|c|c|}
\hline \multirow{2}{*}{ Fixed Carbon } & \multirow{2}{*}{ Total Sulfur } & \multirow{2}{*}{ Volatile } & \multicolumn{6}{|c|}{ Ash (14.00) } & \multirow{2}{*}{ Total } \\
\hline & & & $\mathrm{FeO}$ & $\mathrm{CaO}$ & $\mathrm{SiO}_{2}$ & $\mathrm{MgO}$ & $\mathrm{Al}_{2} \mathrm{O}_{3}$ & Others & \\
\hline 84.00 & 0.50 & 1.50 & 0.14 & 0.48 & 7.50 & 0.15 & 2.72 & 2.89 & 100.00 \\
\hline
\end{tabular}

\subsection{Sintering Pot Tests}

The schemes of the sintering experiment are shown in Table 3, where mixture No.1 (natural acid) is without flux, and with a basicity of 0.33 . The basicities of the mixtures in schemes No.2-4 were $0.50,1.10$, and 2.60 . They were adjusted by quicklime. A sinter blend mixture was used for two-mixed granulation, with a coke content of $3.2 \%$ and a sinter moisture of $7.5 \pm 0.3 \%$. The granule sinter mixture was placed in a $320 \mathrm{~mm}$ diameter sinter pot, with a bed height of $700 \mathrm{~mm}$. The hearth layer was $20 \mathrm{~mm}$, comprised of about $10-15 \mathrm{~mm}$ of sinter. The sintering test parameters were fixed; see Table 4 for a complete list. The sintering process parameters include the flame front speed, weight loss, yield, and productivity. The calculation method is as follows:

$$
\mathrm{V}=\frac{\mathrm{H}_{1}-\mathrm{H}_{2}}{t},
$$

where $\mathrm{V}$ is the flame front speed $(\mathrm{mm} / \mathrm{min}), \mathrm{H}_{1}$ is the height from the feed surface to the cup mouth before loading $(\mathrm{mm}), \mathrm{H}_{2}$ is the height from the feed surface to the cup mouth after loading $(\mathrm{mm})$, and $t$ is the sintering time ( $\mathrm{min})$.

$$
L=\frac{\mathrm{m}_{0}-\left(\mathrm{m}_{1}+\mathrm{m}_{2}\right)}{\mathrm{m}_{0}} \times 100 \%,
$$

where $L$ is the burning loss rate (\%), $\mathrm{m}_{0}$ is the mass of the added sample $(\mathrm{kg}), \mathrm{m}_{1}$ is the mass of the produced sinter $(\mathrm{kg}), \mathrm{m}_{2}$ is the mass of the substrate $(\mathrm{kg})$, and $\mathrm{m}_{2}$ is $4.0 \mathrm{~kg}$ in the test.

$$
\mathrm{Y}=\frac{\mathrm{W}_{1}}{\mathrm{~W}_{2}}
$$

where $\mathrm{Y}$ is the yield of the sinter, $\mathrm{W}_{1}$ is the weight of the sinter with a particle size greater than $5 \mathrm{~mm}(\mathrm{~kg})$, and $\mathrm{W}_{2}$ is the total weight of the sinter $(\mathrm{kg})$.

$$
P=\frac{\mathrm{Ms} \times \mathrm{y}}{\mathrm{A} \times t}
$$

where $P$ is the unit productivity $\left(\mathrm{t} /\left(\mathrm{m}^{2} \cdot \mathrm{h}\right)\right), \mathrm{M}_{\mathrm{S}}$ is the mass of the sinter cake $(\mathrm{t}), \mathrm{y}$ is the yield ( $>5 \mathrm{~mm}$ ) of the product sinter $(\%), A$ is the cross-section area of the sinter pot $\left(\mathrm{m}^{2}\right)$, and $t$ is the sintering time (h). Both A and Ms are considered a constant. 
Table 3. Ore-matching scheme of sintering (\%).

\begin{tabular}{ccccccccccc}
\hline Items & PVTM Ore & YD Ore & MF Ore & ZF Ore & Return Fines & Waste Slag & BF Dust & Coke Content & Basicity & Type \\
\hline 1 & $38-43$ & 30 & 3 & 5 & 20 & 1.5 & 1 & 3.2 & 0.33 & Acid \\
2 & $37-42$ & 30 & 3 & 5 & 20 & 1.5 & 1 & 3.2 & 0.50 & Acid \\
3 & $32-37$ & 30 & 3 & 5 & 20 & 1.5 & 1 & 3.2 & 1.10 & Self-fluxing \\
4 & $26-31$ & 30 & 3 & 5 & 20 & 1.5 & 1 & 3.2 & 2.60 & High-basicity \\
\hline
\end{tabular}

Table 4. Parameters of the sintering test.

\begin{tabular}{cc}
\hline Bed height: $700 \mathrm{~mm}$ & Sintering pot diameter: $320 \mathrm{~mm}$ \\
Ignition suction: $6.0 \mathrm{kPa}$ & Sintering suction: $10.0 \mathrm{kPa}$ \\
Ignition temperature: $1000{ }^{\circ} \mathrm{C}$ & Ignition time: $2 \mathrm{~min}$ \\
Fuel level in blend mix: $3.2 \%$ & Moisture: $7.5 \pm 0.3 \%$ \\
Return fines content: $20 \%$ & Height of hearth layer: $20 \mathrm{~mm}$ \\
Basicity $\left(\mathrm{R}=\mathrm{CaO} / \mathrm{SiO}_{2}\right)=0.33,0.50,1.10,2.60$ & Pelletizing time: $5 \mathrm{~min}$ \\
\hline
\end{tabular}

The sinter cake was crushed with a rake crusher with $40 \mathrm{~mm}$ gaps between the rakes. This was followed by a shattering test, where the crushed sinter was dropped thrice from $2 \mathrm{~m}$. The sinter was finally divided into 6 sizes: $>40 \mathrm{~mm}, 25-40 \mathrm{~mm}, 16-25 \mathrm{~mm}, 10-16 \mathrm{~mm}$, 5-10 $\mathrm{mm}$, and $<5 \mathrm{~mm}$ to evaluate the metallurgical properties.

\subsection{Metallurgical Properties Tests}

The metallurgical properties of the PVTM sinter were determined according to ISO3271, ISO-4696, and ISO-7215, which included the TI, RDI, and RI.

There was not a standard method to determine the softening properties because the sinter was not a pure crystalline substance and did not have a fixed melting point (there was a specific temperature zone for the soft-melting). Prior to the reduction and smelting experiments, the charging method simulated the blast furnace charging conditions [9]. Coke, $20 \mathrm{~mm}$ in height, was put in the bottom of the graphite crucible (Shenyang Graphitecrucible Factory, Shenyang, China) and $500 \mathrm{~g}$ PVTM sinters were put on the nether coke, together with coke $40 \mathrm{~mm}$ in height in a PVTM sinter. The size of the PVTM sinter samples and the coke were all 10-12.5 $\mathrm{mm}$. The schematic diagram of the experimental apparatus is shown in Figure 1. The experimental conditions for conducting softening and melting tests are shown in Table 5.

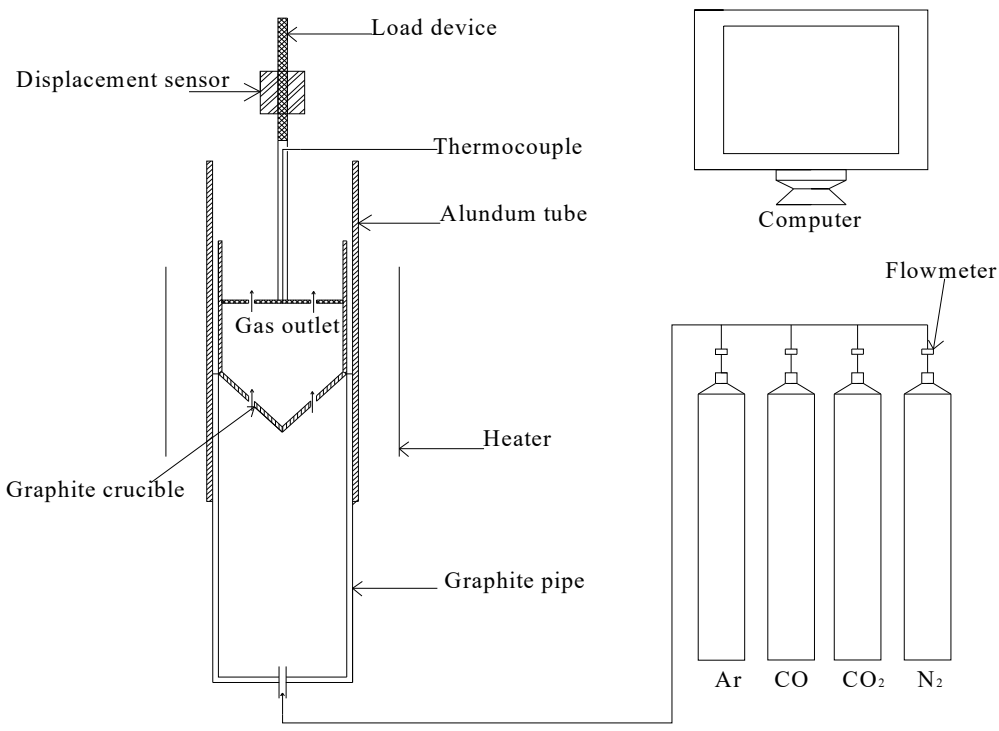

Figure 1. Schematic diagram of experimental softening and melting device. 
Table 5. Experimental conditions for conducting softening and melting tests.

\begin{tabular}{|c|c|c|c|c|}
\hline Temperature Range & $0-400^{\circ} \mathrm{C}$ & $400-900{ }^{\circ} \mathrm{C}$ & $900-1020^{\circ} \mathrm{C}$ & $1020^{\circ} \mathrm{C}$-Dripping Temperature \\
\hline Gas composition & $\begin{array}{l}\mathrm{N}_{2} 100 \% \\
3 \mathrm{~L} / \mathrm{min}\end{array}$ & $\begin{array}{c}\mathrm{N}_{2} 60 \%, 9 \mathrm{~L} / \mathrm{min} \\
\mathrm{CO} 26 \%, 3.9 \mathrm{~L} / \mathrm{min}\end{array}$ & \multicolumn{2}{|c|}{$\begin{array}{l}\mathrm{N}_{2} 70 \%, 10.5 \mathrm{~L} / \mathrm{min} \\
\mathrm{CO} 30 \%, 4.5 \mathrm{~L} / \mathrm{min}\end{array}$} \\
\hline Furnace ramping rate & $10^{\circ} \mathrm{C} / \mathrm{min}$ & $10^{\circ} \mathrm{C} / \mathrm{min}$ & $3^{\circ} \mathrm{C} / \mathrm{min}$ & $5^{\circ} \mathrm{C} / \mathrm{min}$ \\
\hline
\end{tabular}

\subsection{Characterization Methods}

The PVTM sinter samples with varying coke ratios were treated with coarse sandpaper after being encapsulated by resin, then treated with a relatively smooth frosted glass panel and polished in a polishing machine [10]. Mineralogical analysis of the samples was performed with a Leica DM1750M metallographic microscope (Leica, Wetzlar, Germany) and SSX-550 scanning electron microscope (Shimadzu, Kyoto, Japan).

\section{Results and Discussion}

\subsection{Sintering Process Parameters}

The chemical composition of the sinter is shown in Table 6 . Table 6 shows that the iron content of the sinter after sintering reached more than $50 \%$, which meets the requirements of the ore used in the blast furnace.

Table 6. Chemical composition of sinter (mass fraction, \%).

\begin{tabular}{cccccccc}
\hline Items & $\mathbf{T F e}$ & $\mathbf{C a O}$ & $\mathbf{S i O}_{\mathbf{2}}$ & $\mathbf{V}_{\mathbf{2}} \mathbf{O}_{\mathbf{5}}$ & $\mathbf{A l}_{\mathbf{2}} \mathbf{O}_{\mathbf{3}}$ & $\mathbf{T i O}_{\mathbf{2}}$ & $\mathbf{M g O}$ \\
\hline 1 & 56.75 & 1.79 & 5.49 & 1.31 & 4.06 & 1.94 & 2.23 \\
2 & 56.30 & 2.74 & 5.43 & 1.27 & 4.02 & 1.91 & 2.23 \\
3 & 54.87 & 5.77 & 5.26 & 1.17 & 3.90 & 1.80 & 2.22 \\
4 & 51.62 & 12.63 & 4.86 & 0.92 & 3.61 & 1.57 & 2.19 \\
\hline
\end{tabular}

Figure 2 depicts the sintering process parameters of acid, self-fluxing, and high-basicity PVTM sinters. The results show a large gap between them regarding the flame front speed. The flame front speed of a natural acid sinter $(R=0.33)$ is only $6.91 \mathrm{~mm} / \mathrm{min}$, the rate of an acid sinter $(R=0.50)$ jumps to $12.26 \mathrm{~mm} / \mathrm{min}$, the self-fluxing PVTM sinter $(R=1.10)$ is $14.44 \mathrm{~mm} / \mathrm{min}$, and the highest high-basicity PVTM sinter $(\mathrm{R}=2.60)$ is $19.7 \mathrm{~mm} / \mathrm{min}$. This may be attributed to the permeability of the sintering mixture caused by the gaps in the granulation. The PVTM ore has a coarse granularity, a small surface area (shown in Figure 3), and a poor pelletizing property. The quicklime was slaked into the hydrated lime $\mathrm{Ca}(\mathrm{OH})_{2}$ where it came in contact with the sinter mixture mixing and the granulation stage. The granulation was improved by the bonding effect of $\mathrm{Ca}(\mathrm{OH})_{2}[17,18]$. The temperature of the sinter mixture was increased by the exothermic reactions of hydration, which can ease moisture condensation in the bottom layer of the sinter bed. This decreases the resistance in sintering and improves the permeability. Thus, the more quicklime added, the faster the rate becomes. The weight loss with the high-basicity PVTM sinter was the largest at $15.05 \%$. This is probably due to the highest basicity adjustment by the quicklime. This suggests that as more quicklime is added, the larger the weight loss becomes.

The differences between acid, self-fluxing, and high-basicity PVTM sinters in yields $>5 \mathrm{~mm}$ are seen in Figure 2. The yield of the acid PVTM sinter $(\mathrm{R}=0.50)$ was the highest $(83.1 \%)$, and the second highest was the self-fluxing sinter $(R=1.10)$ with a value of $82.90 \%$. The high-basicity sinter had the lowest value at $78.02 \%$. This might be caused by the acid sinter becoming bonded with the silicate, which needs a large mount of heat to form the liquid phase, while the coke content is constant and the heat released by the $3.2 \%$ coke combustion is not enough to provide a sufficient liquid phase in the natural acid sinter $(R=0.33)$. Thus, the yield is lower than that in the acid sinter $(R=0.50)$. Moreover, the bigger weight loss may cause more pores in the self-fluxing PVTM sinter, which would reduce the yield. Besides, the high-basicity PVTM sinter is mainly bonded by silico-ferrite 
of calcium and aluminum (SFCA) but, due to the precipitation of perovskite $\left(\mathrm{CaO} \cdot \mathrm{TiO}_{2}\right)$ and the biggest weight loss, the yield $(>5 \mathrm{~mm})$ is the lowest.

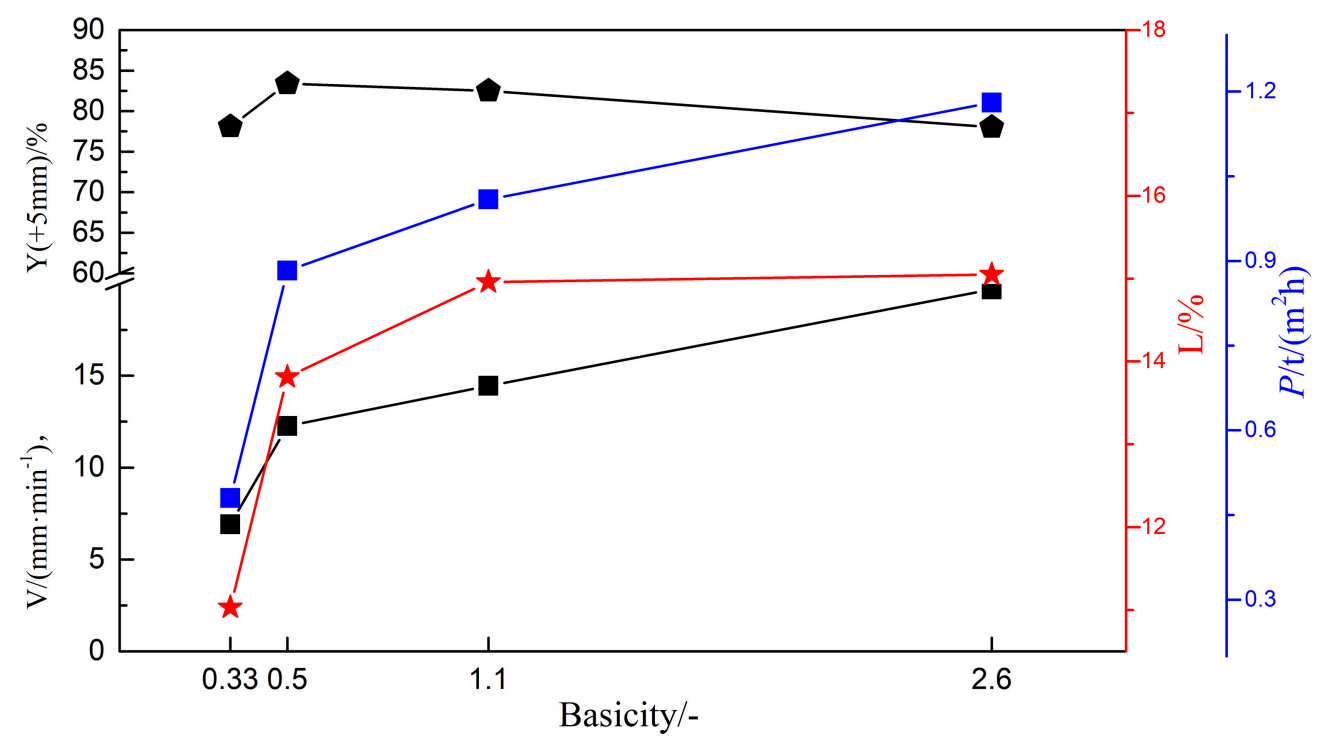

Figure 2. Sintering process parameters of acid, self-fluxing, and high-basicity PVTM sinters.
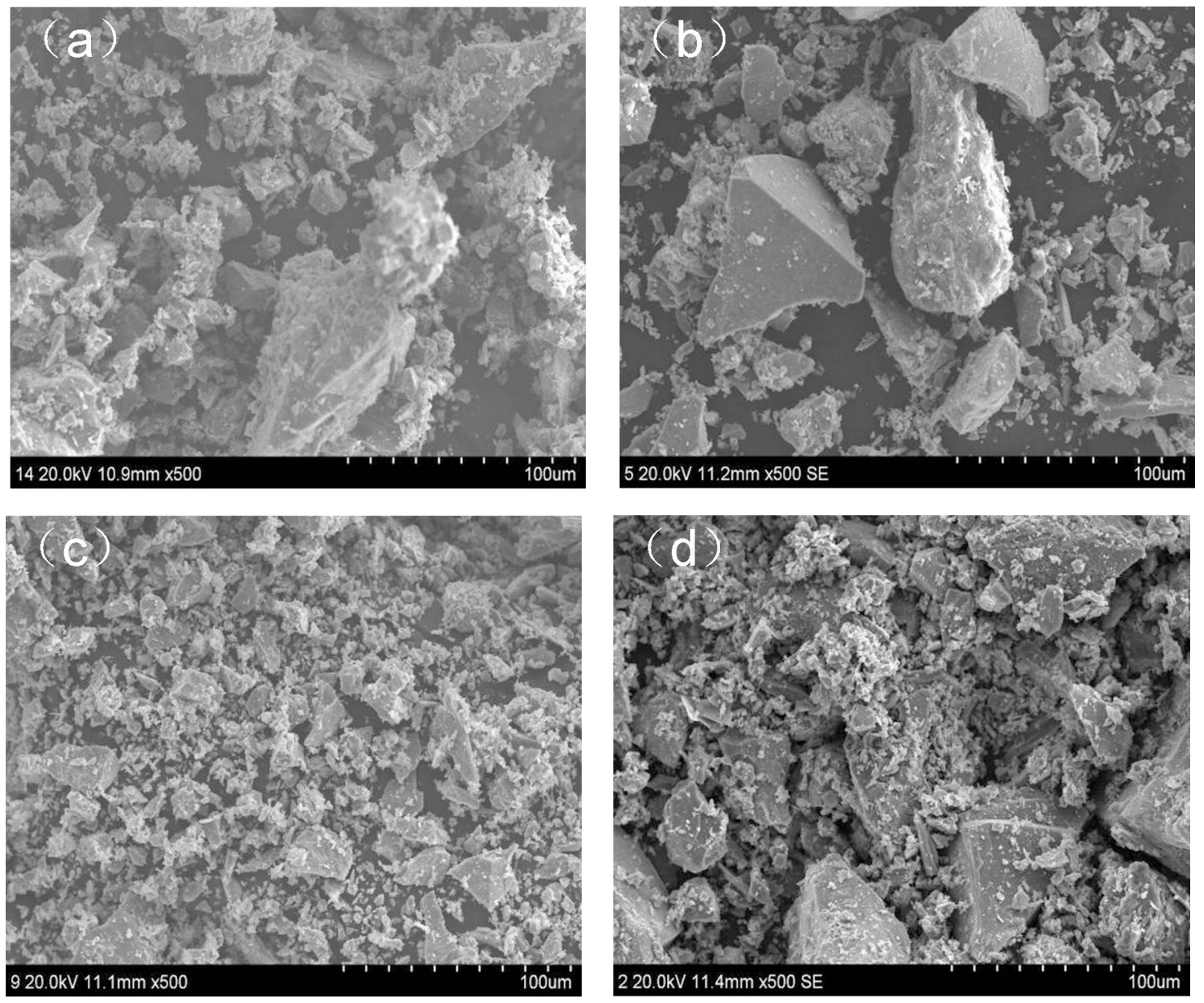

Figure 3. SEM Images of the four PVTM magnetite. (a) A ore; (b) B ore; (c) C ore; (d) D ore. 
Figure 2 depicts the productivity of the PVTM sinters. The flame front speed of the natural acid sinter $(R=0.33)$ was the lowest, it had the longest $t$, and a lower y (Figure 2$)$. Therefore, the natural acid had the lowest $\mathrm{P}\left(0.481 \mathrm{t} /\left(\mathrm{m}^{2} \cdot \mathrm{h}\right)\right)$. The flame front speed for the acid sinter $(R=0.50)$ had a large rise, followed by a large decrease in $t$, and had the highest $\mathrm{y}$. The acid sinter increased the $P$ to $0.883\left(\mathrm{t} /\left(\mathrm{m}^{2} \cdot \mathrm{h}\right)\right)$. The $\mathrm{P}$ had a further increase in the self-fluxing PVTM sinter because the flame front speed further increased while the sintering time had almost no decline. The high-basicity PVTM sinter had the highest $P$, the fastest flame front speed, and the smallest $t$. Additionally, the lowest y had little effect on the final result, as it was slightly smaller than that in the acid or the self-fluxing PVTM sinters.

\subsection{Size Distribution}

Figure 4 shows the size distribution of the acid, the self-fluxing, and the high-basicity PVTM sinters. The results showed that the size distribution of the natural acid PVTM sinter $(R=0.33)$ was uneven, the $10-25 \mathrm{~mm}$ size was fewer along with more of the $>25 \mathrm{~mm}$ and $<5 \mathrm{~mm}$ sizes and, especially, the $>40 \mathrm{~mm}$ size. When the $>40 \mathrm{~mm}$ sinter was placed in the acid PVTM sinter $(R=0.33)$, it was smaller than that in the $R=0.33$ but higher than when in the self-fluxing $(R=1.10)$ and in the high-basicity sinter $(R=2.60)$. There were more $<5 \mathrm{~mm}$-sized sinter, fewer $+40 \mathrm{~mm}$-sized sinter, and more 10-25 mm-sized in the self-fluxing PVTM sinter. The size distribution of the high-basicity $(\mathrm{R}=2.60)$ was the most consistent among the highest $<5 \mathrm{~mm}$-sized sinter, had the most 10-25 mm-sized sinter, and the fewest $+40 \mathrm{~mm}$-sized sinter. These results indicate that the size distribution is dependent on the type, the quantity, and the distribution of the bonding phase. The acid PVTM sinter was primarily bonded by silicate and the sintering process was uneven. This was due to poor granulation and permeability, where the size distribution was not scientific. The high-basicity PVTM sinter was bonded by SFCA, exhibited a uniform microstructure, and had the most sinter sized at $10-25 \mathrm{~mm}$. This is important because the average size of the sinter should be around $20 \mathrm{~mm}$ in Panzhihua Iron and Steel Company (PANGGANG) works $[13,14]$.

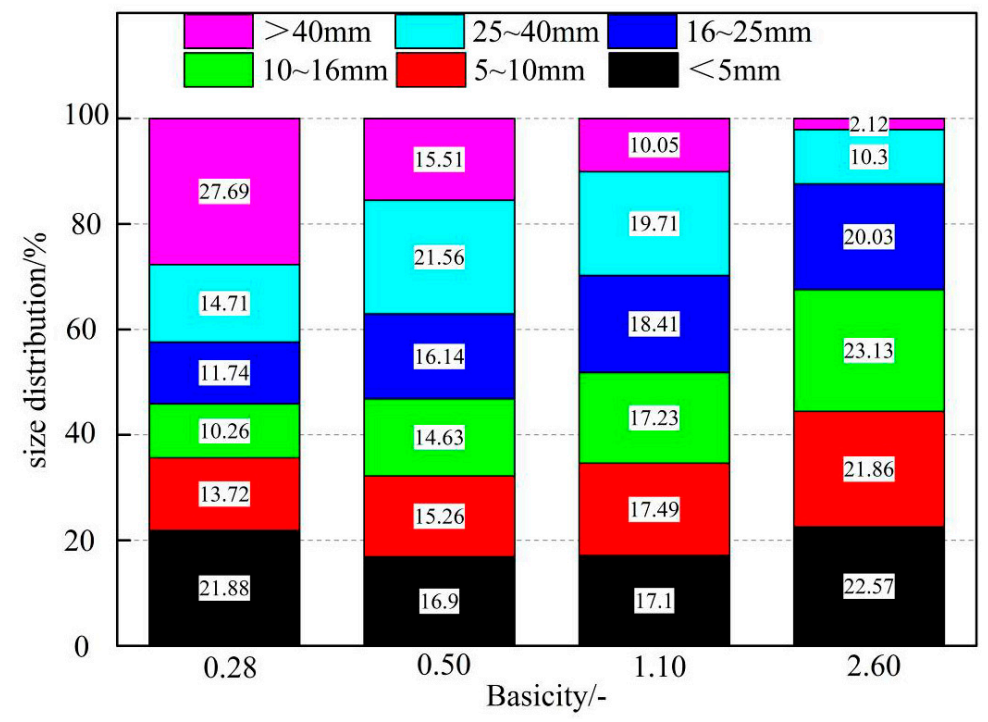

Figure 4. Size distribution of acid, self-fluxing, and high-basicity PVTM sinters.

\subsection{Microstructure and Mineralogy}

The microstructures of acid $(R=0.33 ; R=0.50)$, self-fluxing $(R=1.10)$, and highbasicity $(R=2.60)$ PVTM sinters are shown in Figure 5 . The magnetite and hematite of the vanadium and the titanium sinters were different from the ordinary sinter. The magnetite was a magnetite-ferrotitanium solid solution. The hematite was a titanium-ilmenite solid 
solution. The mineral content of acid $(R=0.33$; $R=0.50)$, self-fluxing $(R=1.10)$ and high-basicity $(R=2.60)$ PVTM sinters is shown in Figure 6.
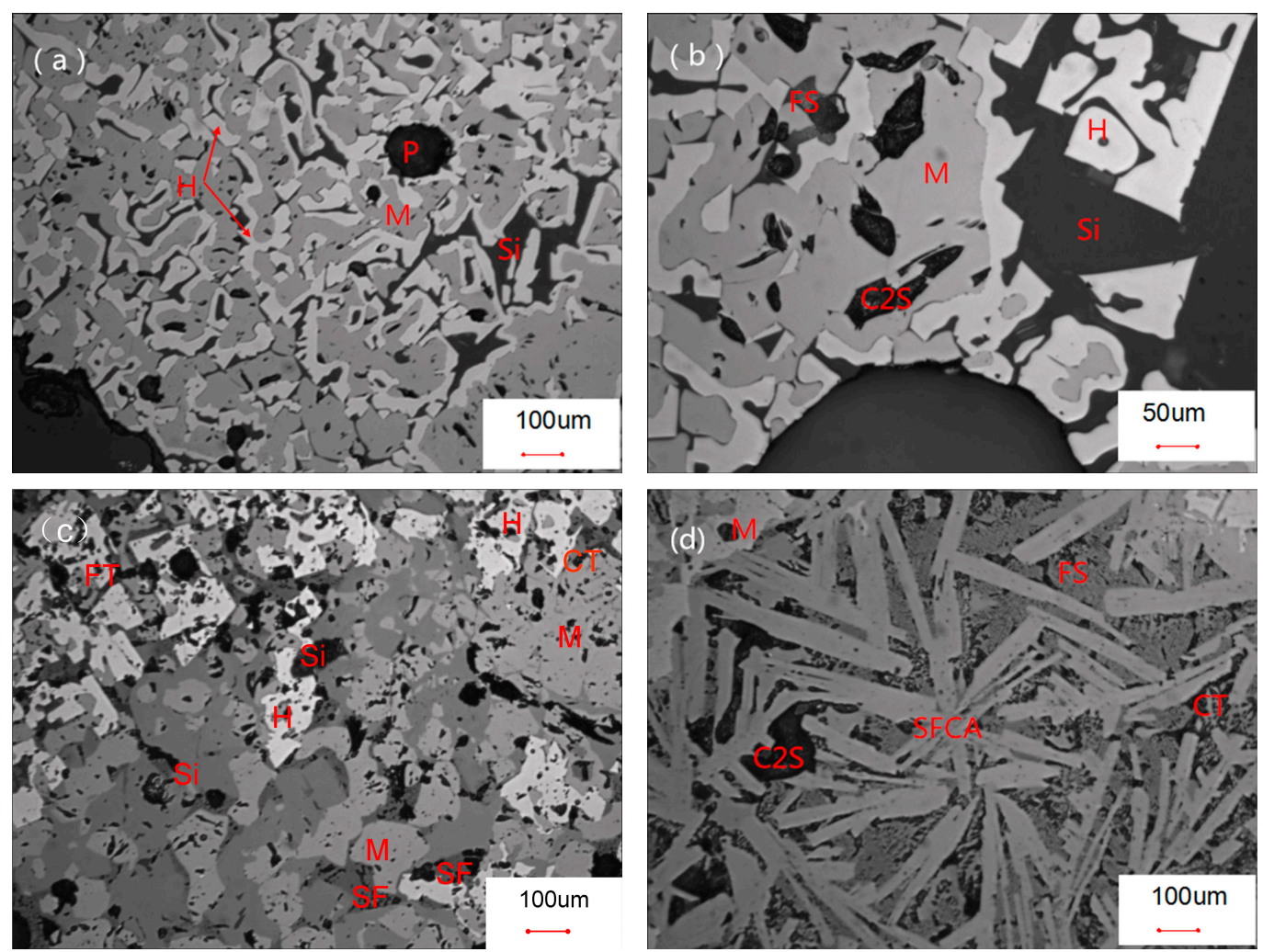

Figure 5. Microstructure images of the PVTM sinter. (a) $\mathrm{R}=0.33$; (b) $\mathrm{R}=0.5$; (c) $\mathrm{R}=1.1$; (d) $\mathrm{R}=2.6$. H: hematite, M: magnetite, Si: silicate, P: pores, C2S: dicalcium silicate, SF: silico-ferrite, SFCA: silico-ferrite of calcium and aluminum, FS: fayalite, CT: perovskite, FT: pseudobrookite.

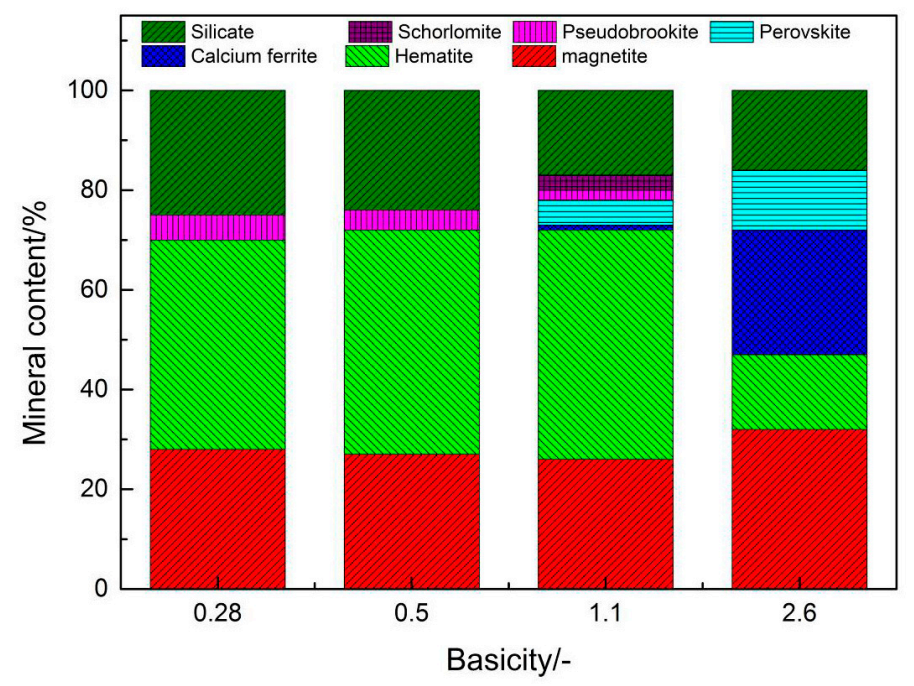

Figure 6. Mineral content of acid, self-fluxing, and high-basicity PVTM sinters.

The main minerals in the acid PVTM sinter were magnetite, hematite, silicate, and pseudobrookite. Approximately $70 \%$ of the magnetite in the raw material was oxidized to the hematite. The hematite and the magnetite were mostly self-shaped or semi-self-shaped zonal crystals, where the crystal was the main bond between the natural basicity PVTM sinter. The silicates were primarily olivine and vitreous that formed a smooth and uniform spongy structure. The microstructure of the acid $(R=0.33,0.50)$ PVTM sinters was dense 
and uniform (Figure 5a,b). There was a small amount in the form of magnetite bonded by silicate that was confirmed by EDS (Figure 7). The structure of the sinter was compact with good intensity. The flame front speed was low due to the time required to oxidize the large amount of magnetite.
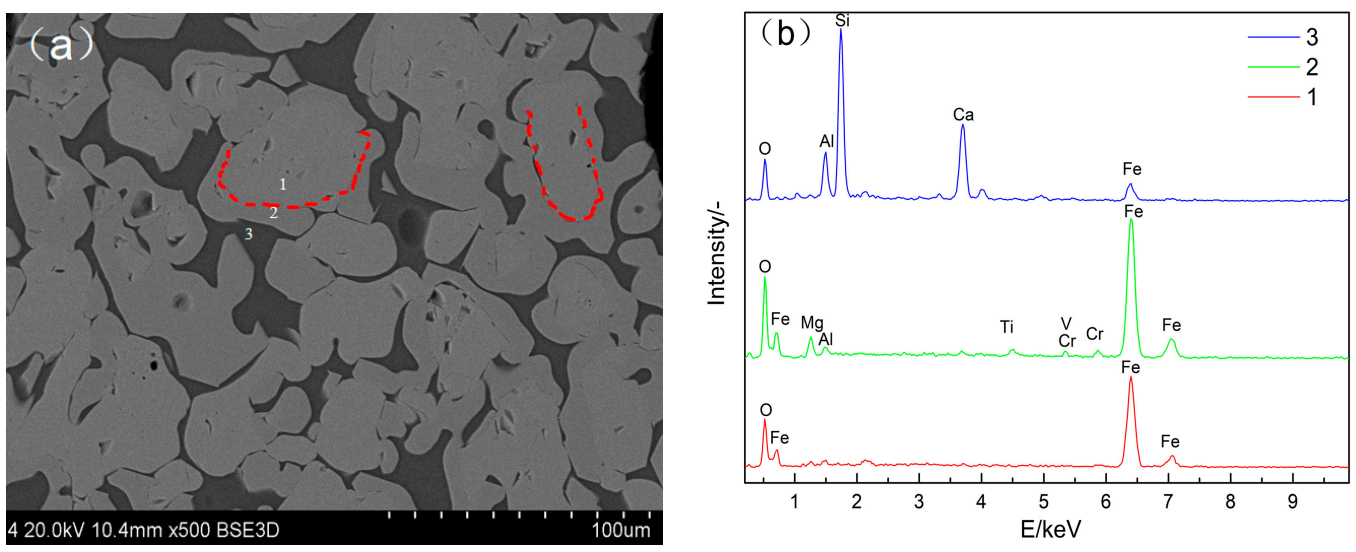

Figure 7. SEM-EDS images of an acid $(\mathrm{R}=0.50)$ PVTM sinter. (a) SEM Image; (b) EDS image.

The primary minerals found in the self-fluxing PVTM sinter were magnetite, hematite, silicate, pseudobrookite, titanium eclogite, perovskite, and SFCA. The crystal effect of the hematite and magnetite were weakened, as most of their particles were filled and cemented during the silicate phase. Small amounts of SFCA and perovskite appeared in the sinter. The calcium iron ore was dispersed between the magnetite and hematite granules in a granular or dendrite form during the sintering process, which weakened the interaction between the two (Figure 5c). The main bonding mode of the self-fluxing PVTM sinter was a silicate bond.

The primary minerals in the high-basicity PVTM sinter were magnetite, hematite, silicate, perovskite, and SFCA (Figure 5d). The content of the magnetite, SFCA, and perovskite was increased in the sinter, and the content of the hematite was decreased. The silicates were primarily dicalcium silicate, and olivine. The high-basicity $(R=2.60)$ PVTM sinter was mostly bonded by SFCA to form a molten microstructure (Figure 8). A small amount of secondary hematite appeared, where there was also a bit of dicalcium silicate, fayalite, and perovskite precipitation around the SFCA. The distribution of the silicate liquid phase in the sinter was unevenly distributed, and the sinter formed an inhomogeneous porous, thin-walled structure due to the increase in perovskite. This affected the intensity of the sinter, although the silicate liquid phase was not obviously increased.

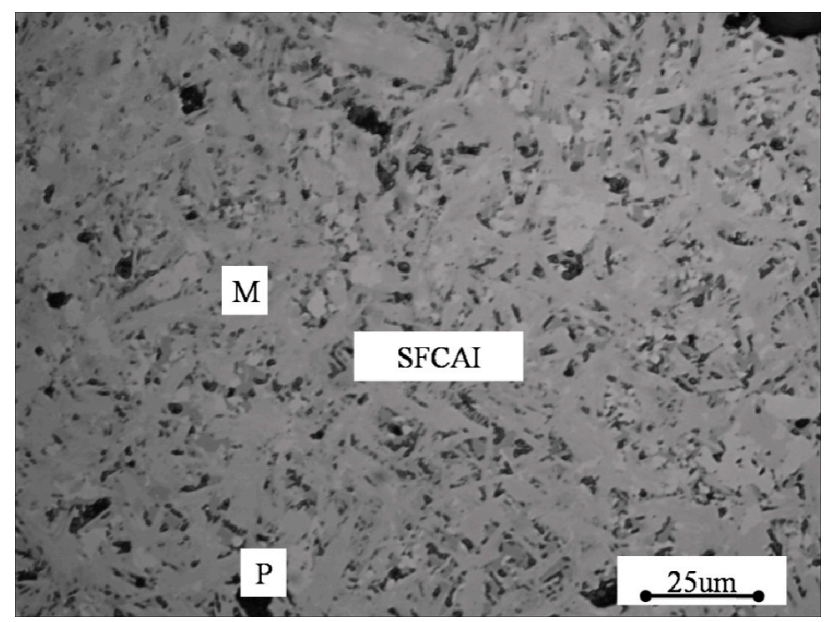

Figure 8. SEM images of a high-basicity $(\mathrm{R}=2.6)$ PVTM sinter. 
To further explore the impact of the basicity on the mineral composition, a thermodynamics analysis on the reaction of the $\mathrm{CaO}$ and some oxides $\left(\mathrm{Fe}_{2} \mathrm{O}_{3}, \mathrm{SiO}_{2}, \mathrm{TiO}_{2}\right)$ was conducted [19]. The $\mathrm{CaO}$ mainly had the following reactions during the sintering process (Figure 9a),

$$
\begin{aligned}
2 \mathrm{CaO}(\mathrm{s})+\mathrm{Fe}_{2} \mathrm{O}_{3}(\mathrm{~s}) & =2 \mathrm{CaO} \cdot \mathrm{Fe}_{2} \mathrm{O}_{3}(\mathrm{~s}), \\
\mathrm{CaO}(\mathrm{s})+\mathrm{Fe}_{2} \mathrm{O}_{3}(\mathrm{~s}) & =\mathrm{CaO} \cdot \mathrm{Fe}_{2} \mathrm{O}_{3}(\mathrm{~s}), \\
2 \mathrm{CaO}(\mathrm{s})+\mathrm{SiO}_{2}(\mathrm{~s}) & =2 \mathrm{CaO} \cdot \mathrm{SiO}_{2}(\mathrm{~s}), \\
3 \mathrm{CaO}(\mathrm{s})+\mathrm{SiO}_{2}(\mathrm{~s}) & =3 \mathrm{CaO} \cdot \mathrm{SiO}_{2}(\mathrm{~s}), \\
\mathrm{CaO}(\mathrm{s})+\mathrm{TiO}_{2}(\mathrm{~s}) & =\mathrm{CaO} \cdot \mathrm{TiO}_{2}(\mathrm{~s}),
\end{aligned}
$$
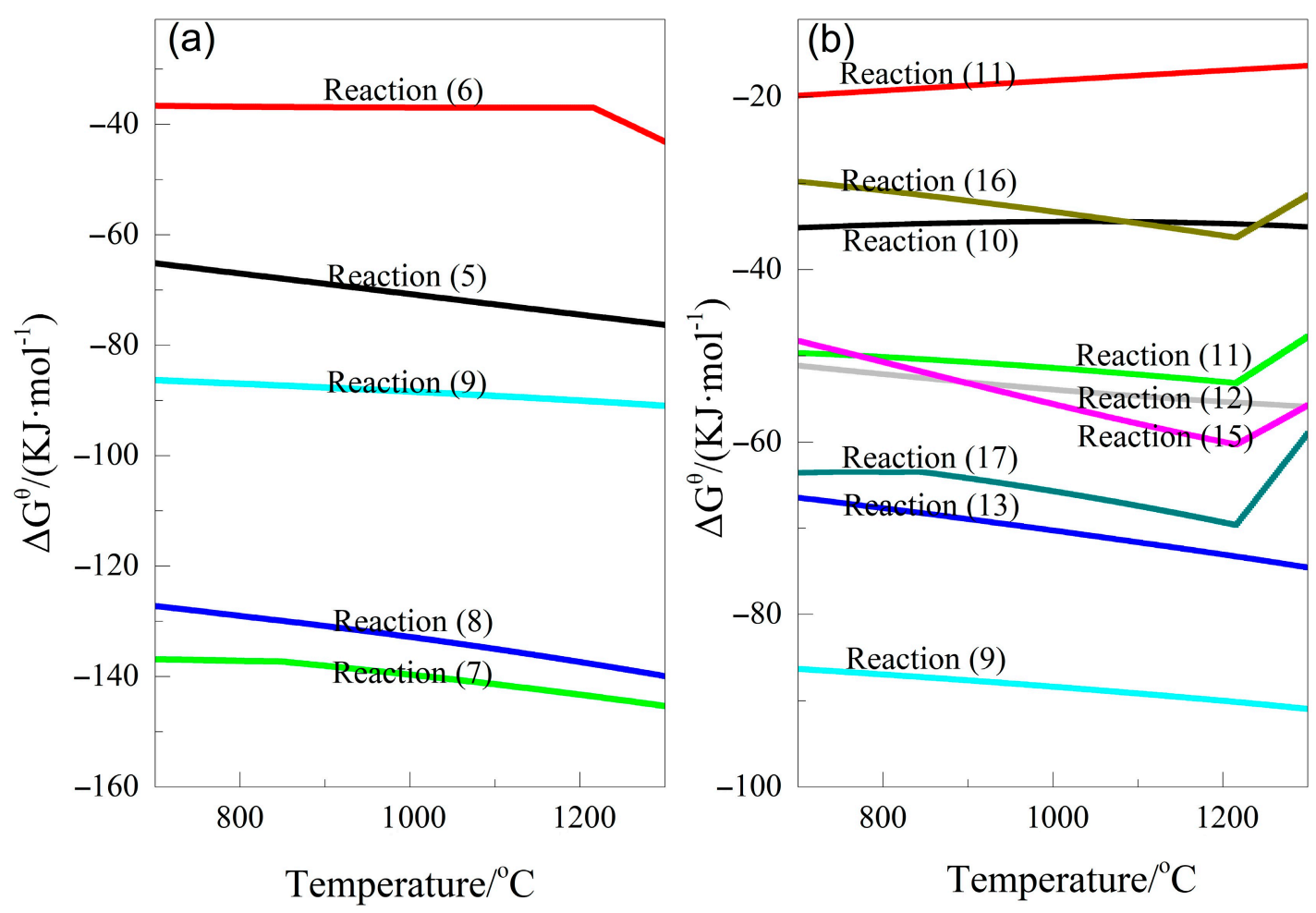

Figure 9. The thermodynamic analysis: (a) Free energy change of $\mathrm{CaO}$ and oxides versus temperature (b) Free energy change of $\mathrm{TiO}_{2}$ and oxides versus temperature.

The order of the thermodynamic trend for the formation of the new minerals shown by the reaction between $\mathrm{CaO}$ and the above oxides was: $2 \mathrm{CaO} \cdot \mathrm{SiO}_{2} ; 3 \mathrm{CaO} \cdot \mathrm{SiO}_{2} ; \mathrm{CaO} \cdot \mathrm{TiO}_{2}$; $2 \mathrm{CaO} \cdot \mathrm{Fe}_{2} \mathrm{O}_{3} ; 2 \mathrm{CaO} \cdot \mathrm{Fe}_{2} \mathrm{O}$. During the actual sintering process of the PVTM magnetite concentrate, there was a large contact area between the $\mathrm{CaO}$ and the iron oxide due to the $\mathrm{SiO}_{2}$. There were good dynamic conditions for the reaction, and it was beneficial in the formation of SFCA and the formation of the liquid phase. Perovskite was more likely to form than SFCA, which was confirmed by the experimental results of the relationship between the mineral composition and the basicity. To ensure the formation of SFCA when producing a high-basicity sinter, perovskite production must be suppressed. This can be accomplished by reducing the content of $\mathrm{TiO}_{2}$ in the concentrate.

Perovskite can be formed in many ways. The thermodynamic analysis showed that $\mathrm{CaO}-\mathrm{TiO}_{2}, \mathrm{CaO}-\mathrm{FeO} \cdot \mathrm{TiO}_{2}, \mathrm{CaO}-2 \mathrm{FeO} \cdot \mathrm{TiO}_{2}, \mathrm{CaO} \cdot \mathrm{Fe}_{2} \mathrm{O}_{3}-\mathrm{TiO}_{2}, \mathrm{CaO} \cdot \mathrm{Fe}_{2} \mathrm{O}_{3}-\mathrm{FeO} \cdot \mathrm{TiO}_{2}$, $\mathrm{CaO} \cdot \mathrm{Fe}_{2} \mathrm{O}_{3}-2 \mathrm{FeO} \cdot \mathrm{TiO}_{2}$ could produce perovskite (Figure $9 \mathrm{~b}$ ). During the actual process, the formation of perovskite is determined by the dynamic conditions of the reaction. The above reactions can be classified as solid-solid and liquid-solid reactions, and a liquid-liquid reaction also was possible. Although perovskite can be formed through the solid-solid 
reaction, the speed is very slow. Occurring at high temperatures $\left(1320-1420{ }^{\circ} \mathrm{C}\right)$, the solidphase reaction between $\mathrm{CaO}$ and $\mathrm{TiO}_{2}$ was accelerated, and perovskite was formed in the sinter. During the cooling process, the perovskite phase first precipitated, which differed from the perovskite generated in a solid-phase reaction. $\mathrm{TiO}_{2}$ existed primarily in $\mathrm{FeO} \cdot \mathrm{TiO}_{2}$ and $2 \mathrm{FeO} \cdot \mathrm{TiO}_{2}$ from within the PVTM magnetite concentrate. Their melting points were $1360{ }^{\circ} \mathrm{C}$. and $1470{ }^{\circ} \mathrm{C}$. $\mathrm{CaO}$ could react with $\mathrm{Fe}_{2} \mathrm{O}_{3}$ to form SFCA at a low melting point, so it was possible to have a liquid-solid reaction (reactions (8) and (9)) and a liquid-liquid reaction (reactions (15) and (16)). This generated perovskite with a high stability and a high melting point that precipitated from the liquid phase. The calcium ferric decomposed and was restored where more $\mathrm{CaO}$ and $\mathrm{TiO}_{2}$ minerals were used to generate perovskite when the temperatures were high, and the atmosphere was reduced. This suggests that if sintering with a low-temperature oxidation, the formation of perovskite could be reduced and the formation of SFCA could be enhanced to improve the sintering properties by increasing basicity.

$$
\begin{gathered}
2 \mathrm{FeO}(\mathrm{s})+\mathrm{TiO}_{2}(\mathrm{~s})=2 \mathrm{FeO} \cdot \mathrm{TiO}_{2}(\mathrm{~s}) \\
\mathrm{FeO}(\mathrm{s})+\mathrm{TiO}_{2}(\mathrm{~s})=\mathrm{FeO} \cdot \mathrm{TiO}_{2}(\mathrm{~s}) \\
\mathrm{CaO}(\mathrm{s})+2 \mathrm{FeO} \cdot \mathrm{TiO}_{2}(\mathrm{~s})=\mathrm{CaO} \cdot \mathrm{TiO}_{2}+2 \mathrm{FeO} \\
\mathrm{CaO}(\mathrm{s})+\mathrm{FeO} \cdot \mathrm{TiO}_{2}(\mathrm{~s})=\mathrm{CaO} \cdot \mathrm{TiO}_{2}(\mathrm{~s})+\mathrm{FeO} \\
\mathrm{CaO} \cdot \mathrm{Fe}_{2} \mathrm{O}_{3}(\mathrm{~s})+\mathrm{TiO}_{2}(\mathrm{~s})=\mathrm{CaO} \cdot \mathrm{TiO}_{2}(\mathrm{~s})+\mathrm{Fe}_{2} \mathrm{O}_{3} \\
2 \mathrm{FeO} \cdot \mathrm{TiO}_{2}(\mathrm{~s})+\mathrm{CaO} \cdot \mathrm{Fe}_{2} \mathrm{O}_{3}(\mathrm{~s})=\mathrm{CaO} \cdot \mathrm{TiO}_{2}(\mathrm{~s})+\mathrm{Fe}_{3} \mathrm{O}_{4}+\mathrm{FeO} \\
\mathrm{CaO} \cdot \mathrm{Fe}_{2} \mathrm{O}_{3}(\mathrm{~s})+\mathrm{FeO} \cdot \mathrm{TiO}_{2}(\mathrm{~s})=\mathrm{CaO} \cdot \mathrm{TiO}_{2}(\mathrm{~s})+\mathrm{Fe}_{2} \mathrm{O}_{3}+\mathrm{FeO} \\
2 \mathrm{CaO} \cdot \mathrm{Fe}_{2} \mathrm{O}_{3}(\mathrm{~s})+\mathrm{SiO}_{2}(\mathrm{~s})=2 \mathrm{CaO} \cdot \mathrm{SiO}_{2}(\mathrm{~s})+2 \mathrm{Fe}_{2} \mathrm{O}_{3}
\end{gathered}
$$

\subsection{Metallurgical Performance}

Figure 10 illustrates the metallurgical performances of the acid, self-fluxing, and highbasicity PVTM sinters. The acid sinter was dependent on the bonding of the silicate, and the natural acid PVTM sinter $(\mathrm{R}=0.33)$ had the lowest TI $(62.93 \%)$. The bonding of the self-fluxing sinter was different from that of the acid sinter, where the uneven distribution of liquid arose from poor granulation. The acid PVTM sinter $(R=0.50)$ had the highest TI $(63.69 \%)$, due to the uniform microstructure, the sufficient liquid, and lack of perovskite. The self-fluxing PVTM sinter had the lowest TI (60.91\%). This may have been caused by the inhomogeneous microstructure, where additional glass and pores occurred as the flame front speed increased with insufficient liquid crystallization. Although no SFCA was present, perovskite would result in the lowered TI. The high-basicity PVTM sinter had a higher TI $(63.51 \%)$, because it was bonded by SFCA, which had a high strength. The TI had a slightly smaller value than the acid PVTM sinter $(R=0.50)$, due to the amount of precipitation by the perovskite.

The $\mathrm{RDI}_{+3.15}$ of acid was $\mathrm{R}=0.33,0.50$ with a high-basicity of $\mathrm{R}=2.60$. The PVTM sinter was higher than $70 \%$, which meets the requirements for a $\mathrm{BF}$, except the self-fluxing $\mathrm{RDI}_{+3.15}$ that had a value of $50.81 \%$. The acid PVTM sinter had a high $\mathrm{RDI}_{+3.15}$ value. This may be attributed to the bonding phases, which were primarily silicate as fayalite with a high FeO. A 1\% increase in FeO improved the RDI by 4 points [20]. There was little hematite present, which was the main reason the sinter had a reduced degradation during the phase transformation of $\mathrm{Fe}_{2} \mathrm{O}_{3} \rightarrow \mathrm{Fe}_{3} \mathrm{O}_{4}$. This was associated with a volume increase of $10 \%$, which led to degeneration during the reduction process at $450-500{ }^{\circ} \mathrm{C}[12,21,22]$. Another cause for the high $\mathrm{RDI}_{+3.15}$ value could be the uniform microstructure, sufficient liquid, few pores, and lack of perovskite. Additional pores appeared when the maximum weight loss was achieved, the secondary hematite from SFCA decomposed, and the phase transformation of dicalcium silicate $\left(C_{2} S\right)\left(\beta-C_{2} S \rightarrow \gamma-C_{2} S\right)$ occurred. These factors combined to cause the $\mathrm{RDI}_{+3.15}$ value to be lower than the acid PVTM sinter, even though it was bonded by a high strength SFCA. The self-fluxing PVTM sinter had the lowest $\mathrm{RDI}_{+3.15}$ 
value, which was likely due to the uneven bonding phase, the presence of perovskite, the pores, and the lack of a high-strength SFCA. Additionally, Figure 11 shows that the vanadium and titanium sintered ore had a good reduction performance and, with the soda ore basicity increased, its reduction performance improved.

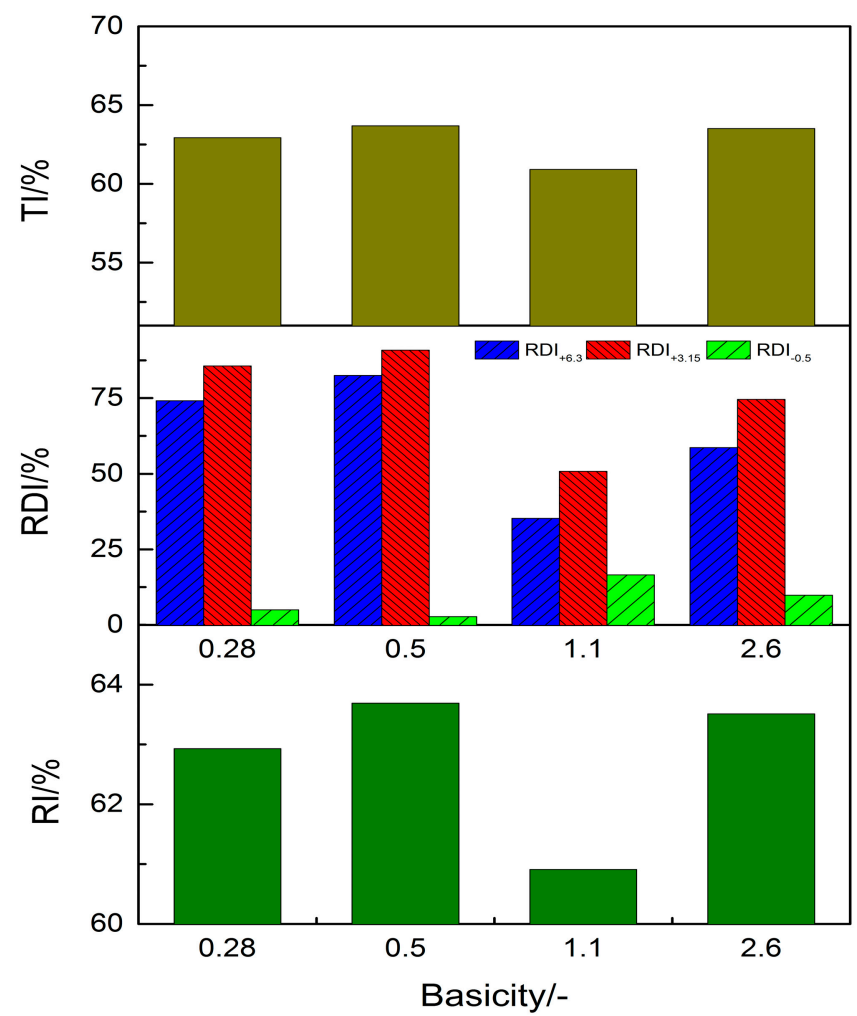

Figure 10. Metallurgical performance of acid, self-fluxing, and high-basicity PVTM sinters.

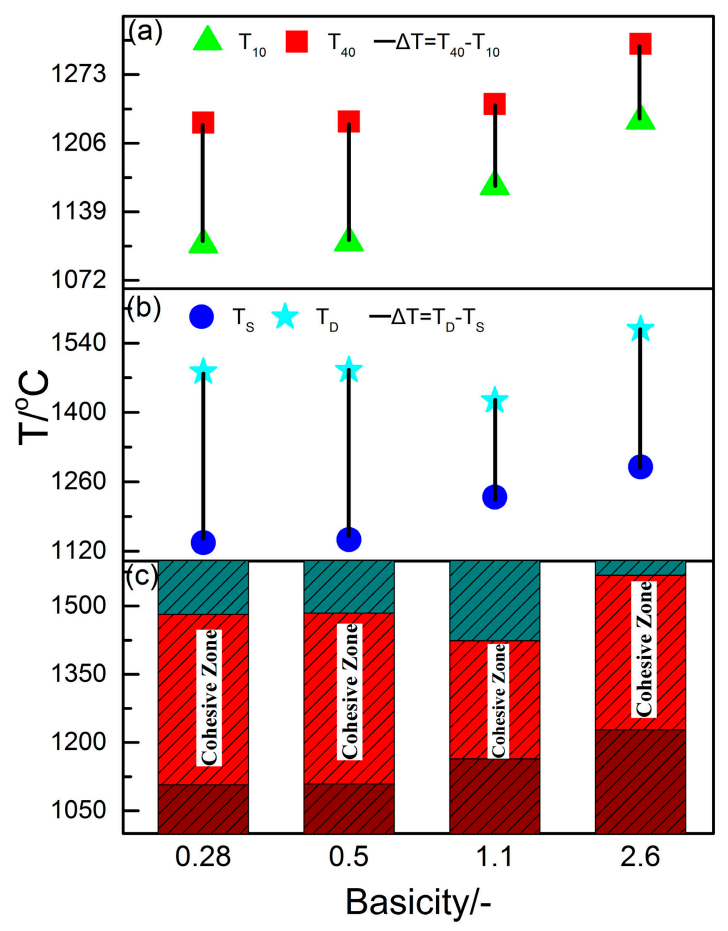

Figure 11. Softening-melting-dripping properties of acid, self-fluxing, and high-basicity PVTM sinters. (a) Softrning zone; (b) Melring-dripping zone; (c) Cohesive zone. 
Figure 11a shows the softening start temperature $\left(\mathrm{T}_{10}\right)$, softening temperature $\left(\mathrm{T}_{40}\right)$, and softening zone $\left(\mathrm{T}_{40}-\mathrm{T}_{10}\right)$ of the acid, self-fluxing, and high-basicity PVTM sinters. The results show that $\mathrm{T}_{40}$ and $\mathrm{T}_{10}$ are also on the rise with the increase in the basicity of the sinter. The reason is the iron olivine is gradually converted to calcic olivine, and the softening temperature of the sinter is promoted. Accompanying the increase in the basicity, hematite, magnetite, and calcium ferrite restore faster, so it causes the speed of the softening temperature to increase faster. The softening zones of the self-fluxing sinter and high-basicity sinter $\left(\mathrm{T}_{40}-\mathrm{T}_{10}\right)$ are obviously showing a narrowing trend.

Figure $11 \mathrm{~b}$ shows the melting start temperature $\left(\mathrm{T}_{\mathrm{S}}\right)$, melting-dripping end temperature $\left(\mathrm{T}_{\mathrm{D}}\right)$, and melting-dripping zone $\left(\mathrm{T}_{\mathrm{D}}-\mathrm{T}_{\mathrm{S}}\right)$ of acid, self-melting, and high-basicity PVTM sinters. The $\mathrm{T}_{\mathrm{S}}$ value of the acid sinter is low, and the content of the $\mathrm{T}_{\mathrm{D}}$ is high, which leads to the widest point of $\left(\mathrm{T}_{\mathrm{D}}-\mathrm{T}_{\mathrm{S}}\right)$. This is due to the higher content of $\mathrm{SiO}_{2}$ compared to the content of $\mathrm{CaO}$. During the reduction process it mainly forms low melting materials such as iron silicate, and the acid slag that it produces has a high viscosity, and poor liquidity, which causes the slag iron only to drop off in high temperatures, leading $\left(\mathrm{T}_{\mathrm{D}}-\mathrm{T}_{\mathrm{S}}\right)$ to increase. The Ts of the melting sinter is increased, mainly because the reduction degree rises with the additional basicity, and the $\mathrm{FeO}$ in the slag decreases accordingly, causing the melting point of the slag to rise, and the $\left(\mathrm{T}_{\mathrm{D}}-\mathrm{T}_{\mathrm{S}}\right)$ to narrow. Regarding a high basicity sinter, when the ratio of the alkaline oxide in the slag and acid oxides is more than that in the silicate, to continue to improve the $\mathrm{CaO}$ in the molten pool with the temperature not high enough, it cannot melt or separate as a solid precipitation of compounds $(2 \mathrm{CaO} \cdot \mathrm{SiO} 2)$ with a high melting point. Additionally, it increases the viscosity of the molten slag, which is not conducive to drip, so there is a trend for $\left(\mathrm{T}_{\mathrm{D}}-\mathrm{T}_{\mathrm{S}}\right)$ to widen.

Figure $11 \mathrm{c}$ is the softening-melting zone of the acid, self-fluxing, and high-basicity PVTM sinters. Acid sinter, due to the low softening start temperature, will form the slag earlier with a higher distilling temperature, which causes a wider softening-melting zone; therefore, it will cause a bad blast furnace permeability, impeding gas from flowing through smoothly, and is unfavorable to burden descent. While the basicity of the self-fluxing sinter increases, the sinter softening start temperature begins to increase, and the softeningmelting zone starts to decrease in a good trend but, in a basicity of 2.6, the sinter's dripping start temperature is too high, which is not conducive to the operation of the blast furnace.

Figure 12 shows the gas permeability index of acid, self-fluxing, and high-basicity PVTM sinters. The gas permeability index, namely the $S$ value, was calculated according to the parameters during reduction and smelting with the equation $S=\int_{T_{S}}^{T_{D}}\left(\Delta P-\Delta P_{S}\right) d T$, which is referred to in previous studies [23]. $\Delta$ Ps is the external static load when the temperature reaches the melting start temperature and $\Delta \mathrm{P}$ is the external static load at a different time. Figure 12 shows that the $S n$ value of the acid sinter and the high-basicity sinter is larger, and the characteristic value of the self-fluxing sinter is the lowest. The acid sinter and high-basicity sinter do not have good permeability, and they are not good to be used in the operation of the blast furnace due to their high characteristic values.

\subsection{Comprehensive Index}

Acid, self-fluxing, and high-basicity PVTM sinters are evaluated by the comprehensive index method, and the higher comprehensive index value calculated, the better are the PVTM sinter performances being evaluated. Here, the comprehensive index method is the same as the method in reference [12], and the chosen indexes and the significance coefficient is the same as that in PANGGANG; the indexes chosen are productivity, TI, and $\mathrm{RDI}_{+3.15}$. The total significance coefficient is 100 , and the significance coefficients of the productivity, TI, and $\mathrm{RDI}_{+3.15}$ levels are 40,30 , and 30, respectively. 


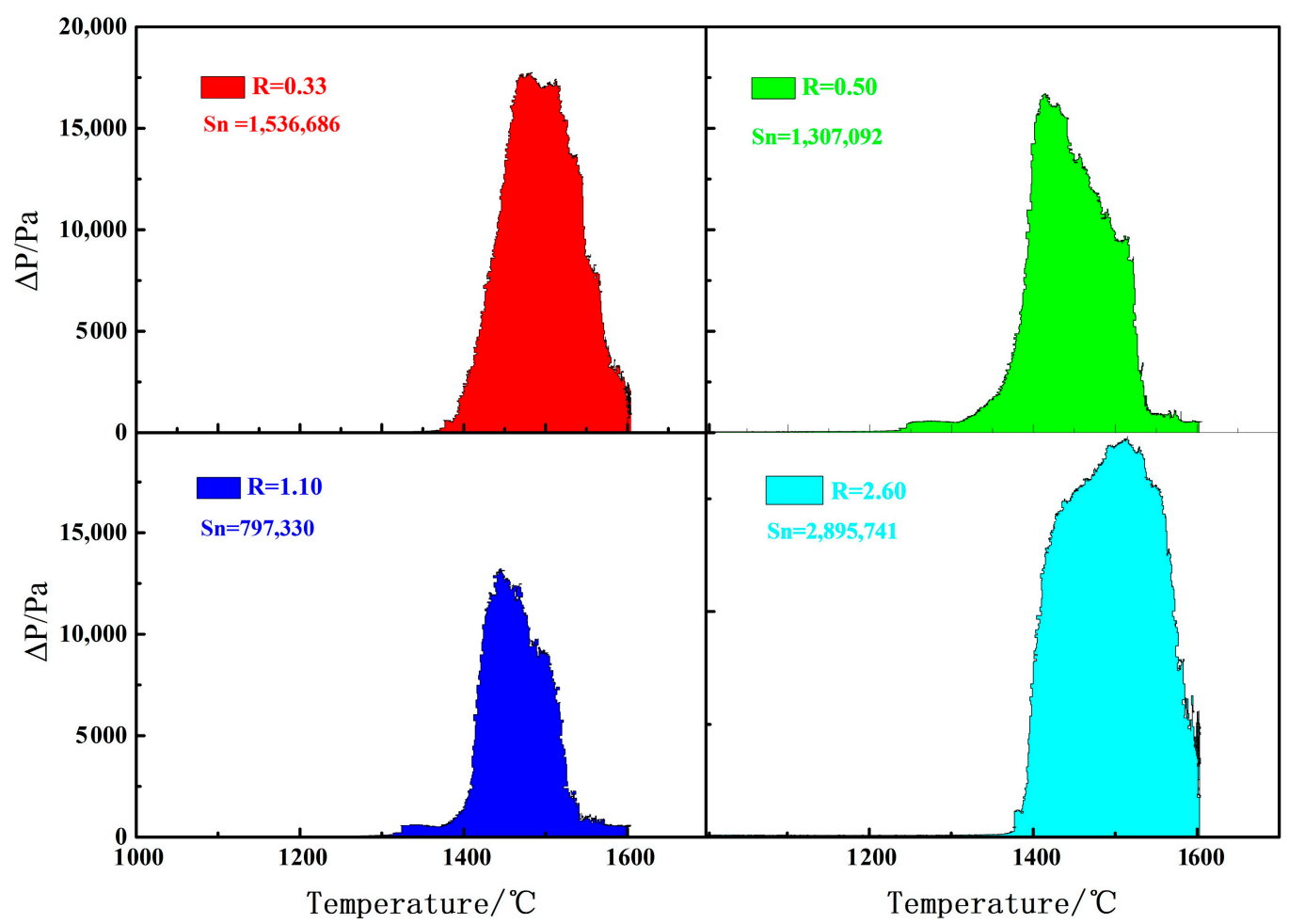

Figure 12. The gas permeability index of acid, self-fluxing, and high-basicity PVTM sinters.

The method is as follows. To facilitate the comparison and analysis, the comprehensive index of the $(R=0.33$, chosen as the better fit) first group is set as a reference and quantified to 100 .

Defining:

$$
F_{i}=f_{i}-f_{1}+100,
$$

where $F_{i}$ is the comprehensive index, $f_{i}$ is the composite index, and $F_{1}=100\left(F_{i}=f_{i}-f_{1}+100\right)$

$$
f_{i}=\sum_{j=1}^{\mathrm{m}} \omega_{j} z_{i j} \cdot(i=1,2, \ldots n ; j=1,2, \ldots m ;),
$$

where $\omega_{j}$ is the unit range coefficient, and $f_{i} \geq 0(i=1,2, \ldots, n)$

$$
\omega_{j}=\frac{W_{j}}{R_{j}}
$$

where $W_{j}$ is the significance coefficient and $\sum_{j} W_{j}=100$ and $R_{j}$ are the range.

$$
R_{j}=\left(\mathrm{z}_{i j}\right)_{\max }-\left(\mathrm{z}_{i j}\right)_{\min ^{\prime}}
$$

where $z_{i 1}$ is the productivity, $z_{i 2}$ is the $T I$, and $z_{i 3}$ is the RDI +3.15 . Table 7.

The calculation process and the results of the comprehensive index are shown in

Table 7 shows the self-fluxing PVTM sinter performance is the worst, then the natural acid PVTM sinter $(\mathrm{R}=0.33)$. The high-basicity PVTM sinter performance is the best, with the highest comprehensive index value, then the acid PVTM sinter $(R=0.50)$. The burden structural model of the blast furnace smelting a vanadium and titanium burden should adopt a 'high-basicity PVTM sinter + acid V-Ti pellet', and when the production capacity of the acid pellet is short, an acid PVTM sinter $(R=0.50)$ could be produced using a surplus sinter plant to replace a part of the acid pellet added to the blast furnace. The novel burden 
structural model was a 'high-basicity PVTM sinter $(\mathrm{R}=2.60)+$ acid V-Ti pellet + acid V-Ti sinter $(\mathrm{R}=0.50)^{\prime}$ used in a BF smelting V-Ti burden, which will require further research into the softening-melting behaviors as it is used in the blast furnace.

Table 7. Evaluation for acid, self-fluxing, and high-basicity PVTM sinters by the comprehensive index.

\begin{tabular}{|c|c|c|c|c|c|}
\hline Items & $\mathrm{Z}_{i 1}$ & $\mathrm{Z}_{i 2}$ & $\mathrm{Z}_{i 3}$ & $\begin{array}{c}\mathrm{fi}=\sum_{j=1}^{\mathrm{m}} \omega_{j} \mathrm{z}_{i j} \\
(i=1,2, \ldots, n ; j=1,2, \ldots, m ;)\end{array}$ & $F_{i}=f_{i}-f_{1}+100$ \\
\hline No.1 & 0.481 & 62.93 & 86.53 & 771.05 & 100.00 \\
\hline No.2 & 0.883 & 63.9 & 90.83 & 801.93 & 130.88 \\
\hline No.3 & 1.009 & 60.1 & 50.81 & 752.25 & 81.20 \\
\hline No.4 & 1.19 & 63.1 & 74.55 & 808.32 & 137.27 \\
\hline$R_{j}=\left(\mathrm{z}_{i j}\right) \quad-\left(\mathrm{z}_{i j}\right)$ & 0.709 & 2.78 & 40.02 & \multirow{3}{*}{\multicolumn{2}{|c|}{ Result: No. 4 > No. $2>$ No.1 > No. 3}} \\
\hline$W_{j}\left(-\max _{\min }\right.$ & 40 & 30 & 30 & & \\
\hline$\omega_{j}=\frac{W_{j}}{R_{j}}$ & 56.42 & 10.79 & 0.750 & & \\
\hline
\end{tabular}

\section{Conclusions}

The acid PVTM sinter had a low flame front speed and low productivity, with an uneven size distribution and poor softening properties. However, it had a high TI and RDI. The performance of the self-fluxing PVTM sinter was the worst. The high-basicity PVTM sinter had the highest flame front speed, highest productivity, a reasonable size distribution, excellent softening properties, and higher TI and RDI values. The comprehensive index value from high to low was the high-basicity $(R=2.60)$, the acid $(R=0.50)$, the natural acid $(\mathrm{R}=0.33)$, and the self-fluxing $(\mathrm{R}=1.10)$ PVTM sinters.

The primary minerals of the acid PVTM sinter were magnetite, hematite, silicate, and pseudobrookite. The microstructure of the acid $(\mathrm{R}=0.33,0.50)$ PVTM sinters was dense and uniform, with a small amount of minerals bonded by silicate. The primary minerals of the self-fluxing $(R=1.10)$ PVTM sinter were magnetite, hematite, silicate, and pseudobrookite, where the crystal effect of the hematite and magnetite was weakened with most of their particles filled and bonded during the silicate phase. The primary minerals of the high-basicity $(\mathrm{R}=2.6)$ PVTM sinter were magnetite, hematite, silicate, perovskite, and SFCA, where the bonding phase was primarily SFCA.

Author Contributions: S.Y. and M.Z. contributed to the material synthesis, performed the experiments, material characterization, data analysis, and paper writing; M.Z. revised the paper and refined the language; T.J. and X.X. contributed to the design of the experiment. All authors have read and agreed to the published version of the manuscript.

Funding: This research was financially supported by the Programs of the National Natural Science Foundation of China (Nos. 51604065, 51674084, 51174051, and 52074081), the National Basic Research Program of China (973 Program) (No.2013CB632603), the Fundamental Funds for the central universities (Nos.150203003, 150202001), the Program of the National Natural Science Foundation of Liaoning Province (20170540316), the National Key Technology R\&D Program (No. 2015BAB19B02), and the Scientific Research Project of Education Department of Liaoning Province(2019LNQN08).

Data Availability Statement: Data available in a publicly accessible repository.

Conflicts of Interest: The authors declare no conflict of interest.

\section{References}

1. Du, H.G. Principle of Smelting Vanadium-Titanium Magnetite in the Blast Furnace; The Science Publishing Company: Beijing, China, 1996; pp. 1-3.

2. Samanta, S.; Goswami, M.C.; Baidya, T.K.; Mukherjee, S.; Dey, R. Mineralogy and carbothermal reduction behaviour of vanadiumbearing titaniferous magnetite ore in Eastern India. Int. J. Miner. Metall. Mater. 2013, 20, 917-924. [CrossRef]

3. Moskalyk, R.R.; Alfantazi, A.M. Processing of vanadium: A review. Miner. Eng. 2003, 16, 793-805. [CrossRef] 
4. Hu, T.; Lv, X.; Bai, C.; Lun, Z.; Qiu, G. Reduction behavior of panzhihua titanomagnetite concentrates with coal. Metall. Mater. Trans. B. 2013, 44, 252-260. [CrossRef]

5. Yang, S.T.; Zhou, M.; Jiang, T.; Xue, X.; Zhang, W. Application of a water cooling treatment and its effect on coal-based reduction of high-chromium vanadium and titanium iron ore. Int. J. Miner. Metall. Mater. 2016, 23, 1353-1359. [CrossRef]

6. Zhou, K.; Song, J.; You, Z.; Xie, H.; Lv, X. Softening-melting Properties and Slag Evolution Behavior of High Titanium Sinter. ISIJ Int. 2020, 60, 1409-1415. [CrossRef]

7. Liu, J.; Cheng, G.; Liu, Z.; Chu, M.; Xue, X. Reduction Process of Pellet Containing High Chromic Vanadium-Titanium Magnetite in Cohesive Zone. Steel Res. Int. 2015, 86, 808-816. [CrossRef]

8. Tang, W.D.; Yang, S.T.; Xue, X.X. Effect of $\mathrm{V}_{2} \mathrm{O}_{5}$ addition on oxidation induration and swelling behavior of chromium-bearing vanadium titanomagnetite pellets with simulated coke oven gas injection into blast furnace. ISIJ Int. 2019, 59, 988-997. [CrossRef]

9. Cheng, G.; Xue, X.; Jiang, T.; Duan, P. Effect of $\mathrm{TiO}_{2}$ on the Crushing Strength and Smelting Mechanism of High-Chromium Vanadium-Titanium Magnetite Pellets. Metall. Mater. Trans. B. 2016, 47, 1-14. [CrossRef]

10. Yang, S.T.; Zhou, M.; Tang, W.; Jiang, T.; Xue, X.; Zhang, W. Influence of Coke Ratio on the Sintering Behavior of High-Chromium Vanadium-Titanium Magnetite. Minerals 2017, 7, 107. [CrossRef]

11. Lv, Q.; Yang, S.T.; Sun, Y.Q.; Hu, X.; Bai, R.G. Effect of Carbon Content in Vanadium Titanium Magnetite on Sintering of Separated Granulating. Iron Steel 2011, 46, 21-25.

12. Zhou, M.; Yang, S.T.; Jiang, T.; Xue, X.X. Influence of MgO in form of magnesite on properties and mineralogy of high chromium, vanadium, titanium magnetite sinters. Ironmak. Steelmak. 2015, 42, 217-224. [CrossRef]

13. Fu, W.G.; Wen, Y.C.; Xie, H.E. Development of intensified technologies of vanadium-bearing titanomagnetite smelting. J. Iron Steel Res. Int. 2011, 18, 7-10. [CrossRef]

14. Fu, W.G.; Xie, H.E. Progress in technologies of vanadium-bearing titanomagnetite smelting in pangang. Steel Res. Int. 2011, 82, 501-504. [CrossRef]

15. Yang, C.J. Acid sinter production and bf smelting effect in jigang. China Metall. 2012, 22, 33-35.

16. Wang, Z.; Pan, B.; Feng, G. Physical Properties of the Binding Phase in Acid Pelletizing Sinter. J. Iron Steel Res. 1999, 11, 1-5.

17. Zhu, D.; Zhang, K.; Pan, J.; Fan, X.; Hu, Y.; John, C. Effect of fluxes on high iron and low silica sintering. J. Cent. South Univ. Thehnol. 2003, 10, 177-182. [CrossRef]

18. Eiki, K.; Yorito, S.; Takazo, K. Influence of Properties of Fluxing Materials on the Flow of Melt Formed in the Sintering Process. ISIJ Int. 2000, 40, 857-862.

19. Huang, X.G. Principles of Iron and Steel Metallurgy, 4th ed.; Metallurgical Industry Press: Beijing, China, 2017 ; pp. 630-635.

20. Umadevi, T.; Nelson, K.; Mahapatra, P.C.; Prabhu, M.; Ranjan, M. Influence of magnesia on iron ore sinter properties and productivity. Steel Res. Int. 2010, 80, 800-807. [CrossRef]

21. Zhang, X.; Zhang, J.; Hu, Z.; Zuo, H.; Guo, H. Effect of $\mathrm{CaCl}_{2}$ on RDI and RI of sinter. J. Iron. Steel Res. Int. 2010, 17, 7-12. [CrossRef]

22. Sun, Y.; Lv, Q.; Wang, X.; Zhang, S.; Zhang, J. Computational Insights into Interactions between Ca Species and $\alpha-\mathrm{Fe}_{2} \mathrm{O}_{3}(001)$. $J$ Iron Steel Res. Int. 2014, 21, 413-418. [CrossRef]

23. Cheng, G.; Gao, Z.; Yang, H.; Xue, X. Effect of Calcium Oxide on the Crushing Strength, Reduction, and Smelting Performance of High-Chromium Vanadium-Titanium Magnetite Pellets. Metals 2017, 7, 181. [CrossRef] 